\title{
Pipeline Embolization Device in Aneurysmal Subarachnoid Hemorrhage
}

\author{
J.P. Cruz, C. O’Kelly, M. Kelly, J.H. Wong, W. Alshaya, A. Martin, J. Spears, and T.R. Marotta
}

\begin{abstract}
BACKGROUND AND PURPOSE: The PED is an FDS designed for the treatment of intracranial aneurysms. Data regarding the use of this device in acute or subacute aSAH is limited to a few case reports or small series. We aimed to demonstrate the feasibility of using an FDS, the PED, for the treatment of ruptured intracranial aneurysms with challenging morphologies.
\end{abstract}

MATERIALS AND METHODS: We conducted a retrospective review of all known patients treated with the PED for aSAH at 4 institutions between June 2008 and January 2012. Pertinent clinical and radiologic information was submitted by individual centers for central collation. The decision to treat with the PED was made on a case-by-case basis by a multidisciplinary team under compassionate use.

RESULTS: Twenty patients (15 women; median age, 54.5 years; IQR, 8.0 years) were found. There were 8 blister, 8 dissecting or dysplastic, 2 saccular, and 2 giant aneurysms. Median time to treatment was 4 days (range, 1-90 days; IQR, 12.75 days) from rupture. Three patients had previous failed treatment. Procedure-related symptomatic morbidity and mortality were 15\%, with 1 (5\%) procedure-related death. Two patients died relative to medical complications, and 1 patient was lost to follow-up. Sixteen patients were available for follow-up, $81 \%$ had a GOS of 5 , and $13 \%$ had a GOS of 4 attributed to a poorer initial clinical presentation. One patient died of urosepsis at 4 months. Occlusion rates were $75 \%$ and $94 \%$ at 6 months and 12 months, respectively. There were 3 delayed complications (1 silent perforator infarct, 2 moderate asymptomatic in-stent stenoses). No symptomatic delayed complications or rehemorrhages occurred.

CONCLUSIONS: The FDS may be a feasible treatment option in the acute or subacute setting of selected ruptured aneurysms, especially blister aneurysms. Ruptured giant aneurysms remain challenging for both surgical and endovascular techniques; at this stage, FDSs should be used with caution in this aneurysm subtype.

ABBREVIATIONS: aSAH = aneurysmal subarachnoid hemorrhage; FDS = flow-diverting stent; GOS = Glasgow Outcome Score; IQR = interquartile range; PED = Pipeline Embolization Device

$\mathrm{T}$ he PED (ev3, Irvine, California) is an FDS designed for the treatment of intracranial aneurysms. The initial published series showed high occlusion rates at 6 months and an acceptable complication rate with its use. ${ }^{1}$ So far, the data regarding the use of this type of device in the setting of acute or subacute aSAH are limited to a few case reports or small series. ${ }^{2-8}$ We report our series

Received July 22, 2012; accepted after revision August 28.

From the Division of Neuroradiology (J.P.C., J.S., T.R.M.), Department of Medical Imaging, St. Michael's Hospital and Division of Neurosurgery (J.S., A.M.), Department of Surgery, University of Toronto, Toronto, Ontario, Canada; Division of Neurosurgery (C.O., W.A.), Department of Surgery, University of Edmonton, Edmonton, Alberta, Canada; Division of Neurosurgery (M.K.), Department of Surgery, University of Saskatchewan, Saskatoon, Saskatchewan, Canada; and Division of Neurosurgery (J.H.W.), Department of Clinical Neurosciences, University of Calgary, Calgary, Alberta, Canada.

Please address correspondence to Thomas R. Marotta, MD, FRCPC, St. Michael's Hospital, 30 Bond St, Toronto, ON, Canada, M5B1W8; e-mail: marottat@smh.ca

http://dx.doi.org/10.3174/ajnr.A3380 of 20 consecutive patients treated with the PED after presenting with aSAH in 4 different centers.

\section{MATERIALS AND METHODS}

We conducted a retrospective review of all known patients treated with the PED for aSAH at 4 institutions between June 2008 and January 2012. Pertinent clinical and radiologic information was submitted by individual centers for central collation. Patient demographic data and relevant comorbidities were registered. The aneurysm type, size, and location; procedural details; clinical presentation at the time of aSAH diagnosis; subsequent imaging; and clinical outcome at discharge and last follow-up were evaluated, by using the GOS as recommended by the World Federation of Neurological Surgeons. ${ }^{9}$

The decision to treat with the PED was made on a case-by-case basis by a multidisciplinary team including vascular neurosurgeons and interventional neuroradiologists, under compassionate use. Informed consent was obtained from substitute decision- 

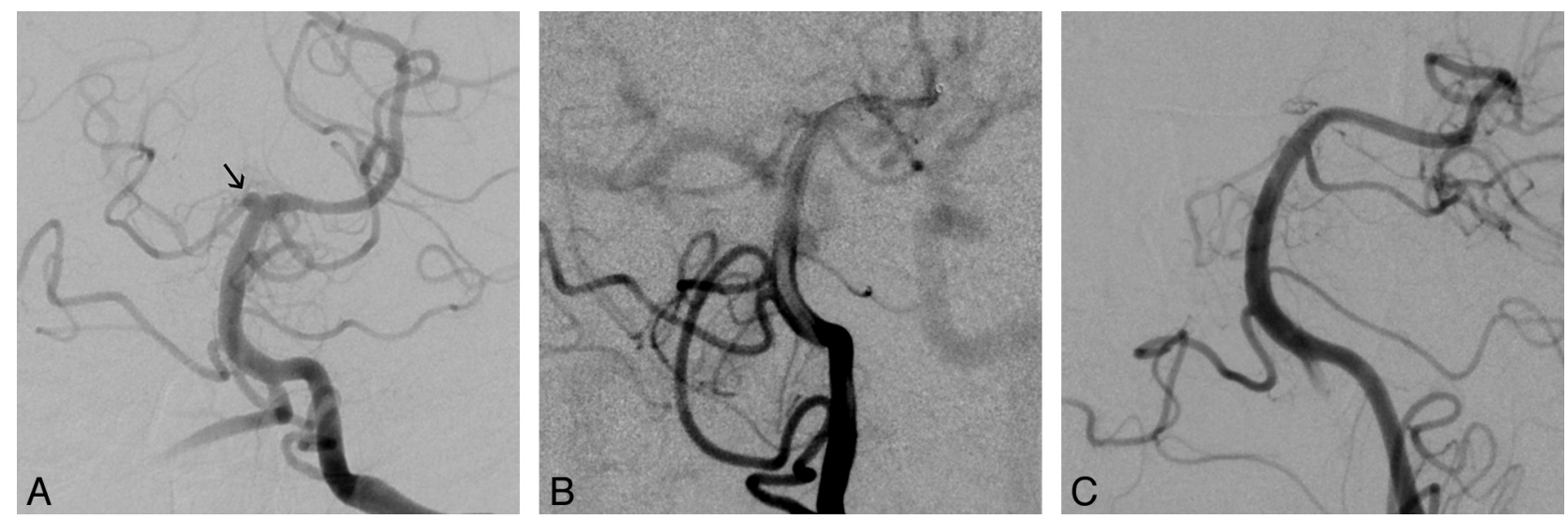

FIG 1. Left vertebral artery anteroposterior angiograms. A, Small, shallow, broad-neck aneurysm at a nonbranching point on the distal basilar artery (arrow), which was not present on the initial CTA, considered a blister aneurysm. B, Control angiogram after a single PED deployment into the left posterior cerebral artery shows persistent filling of the aneurysm, but there was increased stasis on the rotational angiogram (not shown). Note the contrast washout in the basilar artery. C, Two-month follow-up angiogram shows complete occlusion of the aneurysm and reconstruction of the parent vessel, with patency of the covered arteries.

makers, and the experimental nature of the device in aSAH was clearly explained.

In general, patients were pretreated with dual antiplatelet therapy with both acetylsalicylic acid $(325 \mathrm{mg}$ ) and clopidogrel (total dose of $600 \mathrm{mg}$ ) within 24 hours before the procedure. Tests of in vitro platelet function for clopidogrel clinical response were not used. If an external ventricular drain was indicated, it was placed before initiation of dual antiplatelet therapy. Procedural heparinization was used to achieve a targeted activated clotting time of 250-300 seconds. Transfemoral access was obtained with either a $6 \mathrm{~F}$ guide catheter or $6 \mathrm{~F}$ long sheath. Following angiographic evaluation of the targeted aneurysm, an 0.027 -inch microcatheter (Marksman; ev3) was manipulated across the targeted landing zone over an 0.014 -inch microguidewire. Once in position, $\geq 1$ PED was delivered to reconstruct the parent artery. Overlapping devices were used at the discretion of the primary operator to bridge normal arterial segments or achieve the desired flow effect. The decision as to whether to place coils in addition to the PED was left to the discretion of the primary operator, depending on the size and characteristics of the aneurysm. In such cases, an 0.014- or 0.018-inch microcatheter was placed in the aneurysm lumen before PED deployment by using a 5F guide catheter via contralateral femoral access. Loose-packed coiling was then performed after the PED was adequately positioned. At the end of the procedure, control angiography was performed in a working projection and in standard anteroposterior and lateral views for distal vessels.

No heparin reversal or continuous heparin infusion was used postprocedure. Patients were transferred to a dedicated neurosurgical intensive care unit and strictly monitored for the occurrence of vasospasm, rehemorrhage, and procedure-related or unrelated complications.

All patients underwent postprocedural MRA and/or CTA during admission. After discharge, follow-up visits and noninvasive imaging follow-up varied according to the different centers. DSA was performed at 12 months if the initial lesion was too small for reliable assessment with MRA or CTA or if these studies demonstrated persistent filling or in-stent stenosis. Dual antiplatelet therapy was continued for a minimum of 6 months. After this, discontinuation of clopidogrel was left to the discretion of the treating physician, and the patient was maintained on aspirin only.

Demographic data, aneurysm size, days to documented occlusion, and days to last follow-up are expressed in medians and IQRs, given the small sample size (non-normal distribution).

\section{RESULTS}

Twenty patients ( 15 women; median age, 54.5 years; IQR, 8.0 years) presenting with aSAH underwent treatment with the PED. The World Federation of Neurological Surgeons score on admission was $\leq 2$ in 14 patients, 2 in 1 patient, and $\geq 4$ in 5 patients.

There were 16 nonsaccular aneurysms ( 8 blister, 8 dissecting or dysplastic) and 2 saccular and 2 giant aneurysms. Both giant aneurysms failed balloon test occlusion, and a vertebral artery dissecting aneurysm had a subclavian steal, so parent vessel occlusion was contraindicated. Fifteen aneurysms were in the anterior circulation (ICA, 12; MCA, 1; anterior cerebral artery, 2); and 5, in the posterior circulation (basilar artery, 4; vertebral artery, 1). Median aneurysm size was $3 \mathrm{~mm}$ (IQR, $3.05 \mathrm{~mm}$; range, 2-25 $\mathrm{mm})$.

Twelve patients were treated in the acute phase ( $<5$ days), 2 within $5-10$ days, and 6 beyond the peak vasospasm period ( $\geq 10$ days). Median time to treatment was 4 days (range, 1-90 days; IQR, 12.75 days). The patient who was treated 90 days post-SAH had an initially missed aneurysm, with subsequent growth seen in follow-up images. Surgical exploration revealed a blister morphology, so she was referred for PED treatment. Three other patients had prior treatment: 1 early recanalized stent-assisted coiling, 1 surgical clipping with significant aneurysm growth on postoperative DSA; and 1 subtotal coiling 17 days before PED. Fifteen patients were treated with the PED as monotherapy (all 8 blister, 6 dissecting/dysplastic, and 1 saccular aneurysm). Coils were placed in a prior procedure in 1 case of saccular aneurysm and during the same procedure in 4 cases (2 giant, 2 dissecting/ dysplastic). In total, 5 patients received coils during their treatment. The patients treated with the PED and no coils had smaller aneurysms (median, $2.4 \mathrm{~mm}$; IQR, $1.47 \mathrm{~mm}$ ) than the patients who received coils (median, $15 \mathrm{~mm}$; IQR, $10 \mathrm{~mm} ; P<.001$ ). 

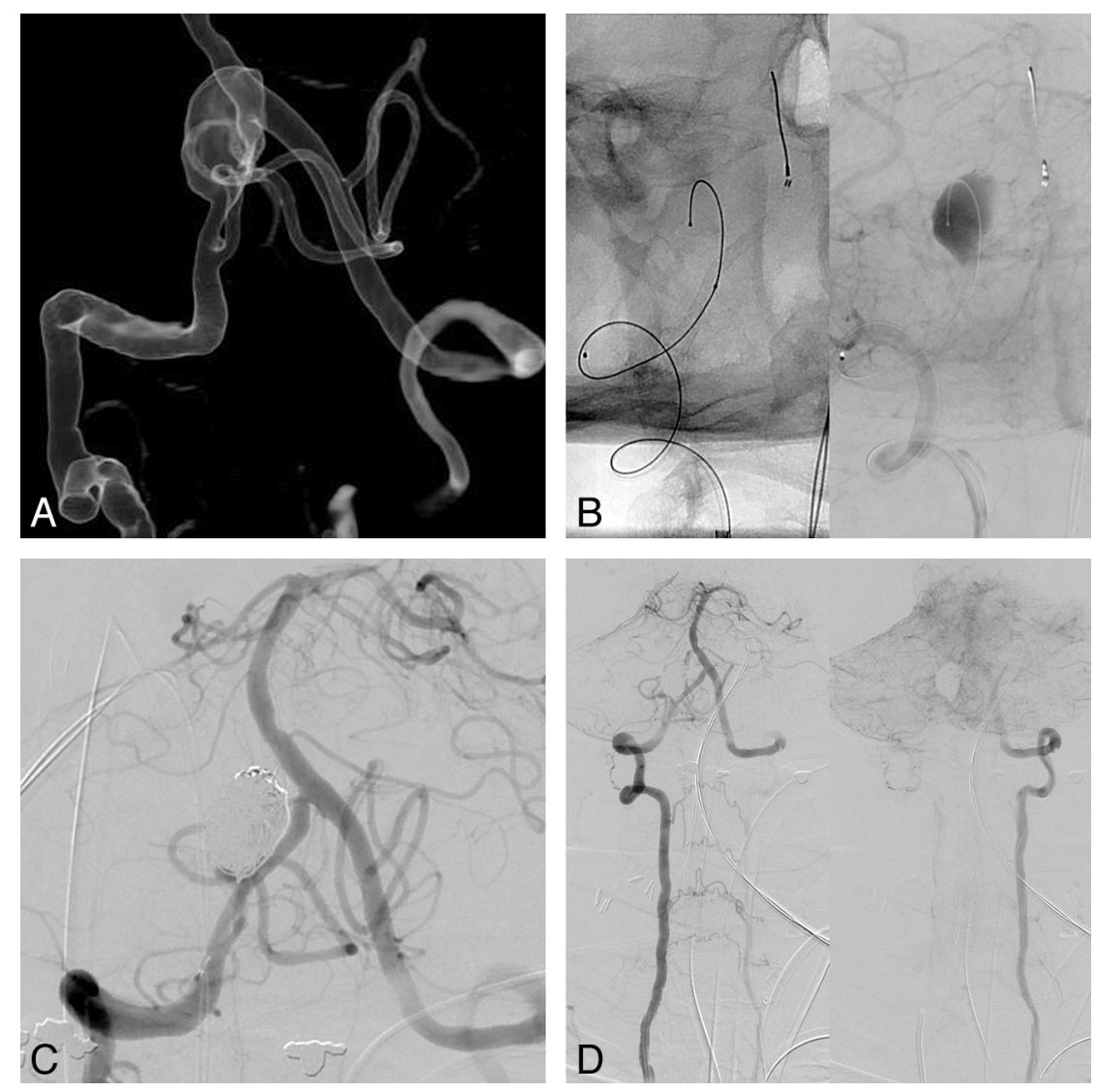

FIG 2. $A, 3 D$ volume-rendered reformat of a right vertebral artery rotational angiogram. The broad-neck aneurysm arising at a nonbranching site of the right intracranial vertebral artery, distal to the PICA origin, was considered a dissecting/dysplastic aneurysm. B, Single-shot image and venous phase right vertebral artery angiogram in working projections after a single PED. There is a 0.014 -inch microcatheter in the aneurysm lumen. Note the contrast stasis in the aneurysm sac. $C$, Control angiogram after loose-packed coiling of the aneurysm sac to increase the thrombosis rate, with good immediate angiographic results. D, Right vertebral artery anteroposterior angiogram showing left subclavian steal, which contraindicated parent vessel occlusion.

external ventricular drains were placed before starting dual antiplatelet therapy in 9 cases, and a patient had a ventriculoperitoneal shunt placed 3 days before the procedure.

There were 4 (20\%) procedure-related complications. These included 2 technical complications: 1 direct carotid cavernous fistula after PED angioplasty, which resolved spontaneously, and 1 ICA dissection seen 7 days later with ICA occlusion and cortical infarcts. One thromboembolic complication occurred, with multiple cortical infarcts, presumably from mural/luminal thrombus dislodging secondary to manipulation of the microcatheter for PED delivery in a partially thrombosed giant aneurysm. One hemorrhagic complication occurred in a patient with a giant aneurysm treated with PED and coils, who developed a parenchymal hematoma within 24 hours, located in the basal ganglia immediately superior to the coil mass, presumably from giant aneurysm rerupture. This patient died 5 days later.

There was 1 treatment failure (5\%) in a patient who underwent a first surgical clipping with significant residual aneurysm on postoperative angiography. A single PED was deployed, and despite initial acceptable placement, the aneurysm grew, requiring another intervention 8 days later, with 2 more overlapping PEDs. No hemorrhagic complications related to external ventric- ular drain removal occurred in this cohort. One patient required a ventriculoperitoneal shunt after the procedure and preoperative platelet transfusion, with no complications. There were 3 asymptomatic delayed complications, including 1 silent perforator infarct at 3-month follow-up MR imaging and 2 moderate in-stent stenoses. No symptomatic delayed complications or delayed rehemorrhages occurred.

At discharge from our institution, 9 patients (45\%) were independent (GOS, $\leq 4)$ and 8 patients had severe disability (GOS, 3); 2 due to procedure-related complications. There were 1 (5\%) procedure-related death and 2 additional non-procedure-related deaths (1 withdrawal of care after failure to improve, 1 esophageal intubation during endotracheal tube exchange in the intensive care unit).

Median follow-up was 179 days (IQR, 199 days), with 1 patient lost to follow-up. On last follow-up, $94 \%$ of the surviving patients $(n=16)$ were independent, with a GOS of 5 in 13 and a GOS of 4 in 2, both attributable to a poorer initial clinical presentation (World Federation of Neurological Surgeons, 4). One patient (GOS, 1) died due to a sepsis 4 months after the aSAH.

Medium-term angiographic follow-up was available in 16 patients. Occlusion rates were $75 \%(12 / 16)$ at 6 months and $94 \%$ at 12 months. Occlusion was documented with DSA in 10, CTA in 4, and MRA in 2 patients.

\section{DISCUSSION}

Since the publication of the International Subarachnoid Aneurysm Trial results, ${ }^{10}$ aneurysm coiling has become the treatment of choice in ruptured aneurysms suitable for endovascular therapy. The PED has emerged as a treatment option for ruptured aneurysms that are otherwise difficult or potentially not treatable by standard means of endovascular embolization.

The attenuated metal weave and porosity of the PED have been designed to redirect the blood flow, decreasing the inflow and outflow jets of the aneurysm, promoting blood stasis and delayed thrombosis, leading to reconstruction of the parent vessel. ${ }^{11}$ These devices are porous self-expandable stents that are able to occlude the aneurysm neck while preserving the patency of the covered arterial branches. ${ }^{12-14}$ The delayed occlusion, as opposed to immediate occlusion seen in endovascular coiling and surgical clipping, and the need for dual antiplatelet therapy have limited their use in acutely ruptured aneurysms. New complications, including delayed parent vessel occlusion, ${ }^{15,16}$ aneurysm rup- 

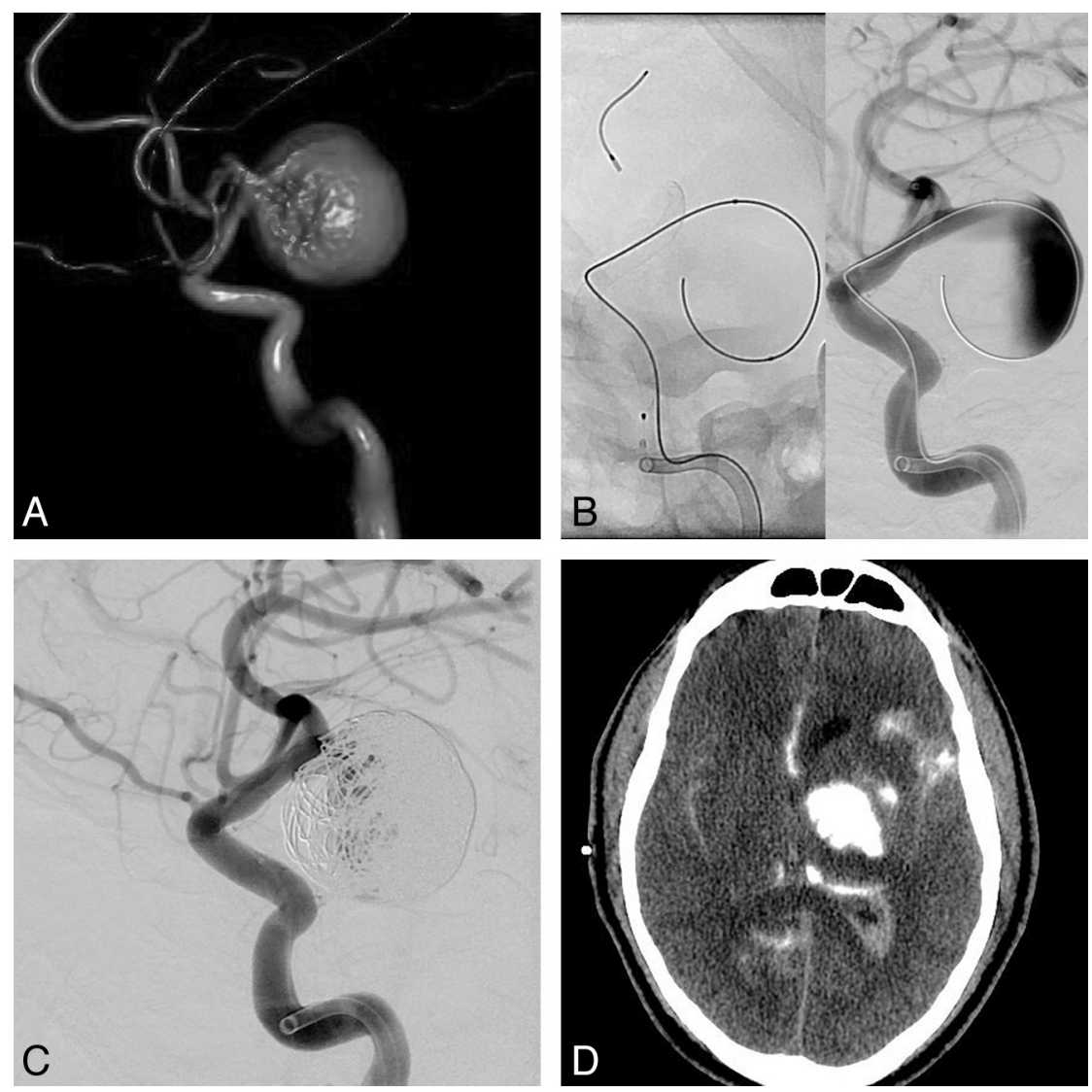

FIG 3. $A, 3 D$ volume-rendered reformat of a left ICA rotational angiogram shows a giant distal supraclinoid ICA aneurysm. $B$, Lateral ICA angiogram after a single PED deployment shows a significant flow effect with contrast stasis and layering within the aneurysm sac. C, Lateral ICA angiogram after loose packing of the aneurysm sac, with higher packing attenuation at the dome near the presumed ruptured site. There is persistent filling of the aneurysm sac and a satisfactory flow effect. $D$, Non-enhanced CT hours after the procedure. The patient had an acute decline in his neurologic status. There is a large parenchymal hematoma with contrast material cranial to the coil mass and in the ventricles and subarachnoid space. The patient died 5 days later secondary to persistent raised intracranial pressure.

ture, ${ }^{17-20}$ and ipsilateral intraparenchymal hemorrhage, ${ }^{21,22}$ are to be considered if the aneurysm is amenable for other treatment strategies.

FDSs are thought to be more thrombogenic than other intracranial stents, ${ }^{23}$ and dual antiplatelet therapy is still considered mandatory. The optimal administration of dual antiplatelet therapy in the acute phase of SAH has yet to be determined. Some authors have suggested that intracranial stents might have a limited role because of the increased rate of hemorrhagic complications. According to a literature review by Bodily et $a l,{ }^{24}$ hemorrhagic complications were seen in $8 \%$ of patients treated with stent-assisted coiling for acutely ruptured intracranial aneurysms. However, a large proportion of these complications were related to external ventricular drain placement rather than aneurysmal early rerupture or parenchymal hemorrhage, which represented $<3 \%$ of all complications. For these reasons, external ventricular drains should be placed before the initiation of dual antiplatelet therapy to minimize the risk of hemorrhagic complications. We did not encounter any hemorrhages related to the external ventricular drain removal or ventriculoperitoneal shunt placement. The data available from stent-assisted coiling studies suggest that dual anti- platelet therapy may be started safely preor postprocedurally in the acute or subacute phase of aSAH, and these data have been transferred to the use of dual antiplatelet therapy in FDSs. The subject remains controversial because large series have not yet been reported and decisions must be made on a case-by-case basis.

Intradural ruptured nonsaccular aneurysms are characterized by a dismal natural history if not diagnosed correctly and promptly treated. Ruptured vertebrobasilar dissecting aneurysms have a high rate of early rehemorrhage, up to $70 \%$ in some series, ${ }^{25-27}$ and are associated with a poor clinical outcome. Blister aneurysms are rare lesions $(0.5 \%-2 \%$ of all $\left.\mathrm{aSAH}^{28}\right)$, classically arising at a nonbranching point of the supraclinoid ICA, but have been described in other locations. ${ }^{23}$ They correspond to a focal wall defect of the internal elastic lamina and media, covered by adventitia with no collagenous proliferation typically seen in aneurysms. ${ }^{29}$ For these reasons, treatment with reconstructive techniques poses a unique challenge.

Surgical clipping, wrapping, and a combination of both have been described as vessel-preserving techniques but still have high morbidity and mortality rates for these aneurysm subtypes. ${ }^{30}$ Coiling with or without stent remodeling, ${ }^{23}$ stent within stent, ${ }^{31}$ and covered stents ${ }^{32,33}$ have been used with mixed results, but recanalization and aneurysm growth remain the major limitation for these treatment modalities because traditional higher porosity stents have significantly less effect over the inflow to the aneurysm sac. ${ }^{34,35}$

The PED has been reported as a treatment alternative in acutely ruptured dissecting and blister aneurysms with good results, though the number of cases continues to be small. ${ }^{2-8}$ The aneurysm occlusion is not immediate compared with coiling and surgical clipping; still, no rehemorrhages have been reported to date. Although there are minimal immediate angiographic changes, the PED may provide some immediate protection by reducing the aneurysm inflow, ${ }^{36}$ with reconstruction of the parent vessel in the long term (Fig 1). Parent vessel occlusion remains the treatment of choice for dissecting aneurysms not related to the PICA origin. The PED should be an alternative to stent-assisted coiling for those vertebral artery dissections that require vessel preservation or for dissecting aneurysms in other vessels. This series, similar to other reports, ${ }^{2,5,37}$ shows good results for blister aneurysms. Other surgical and endovascular approaches have been reported with mixed results. ${ }^{23,28,31,32,38-41}$ As such, the PED should be considered a treatment option in blister aneurysms.

In our series, there were 16 nonsaccular aneurysms. We had no 
rehemorrhages or procedure-related mortality, and $83 \%$ of the patients available for follow-up showed a good long-term clinical outcome. Two patients had a GOS of 4, related to a more severe initial clinical presentation. Aneurysms in the anterior circulation were not considered good surgical candidates or amenable to coiling. The only vertebral artery of this type treated with the PED was not amenable to parent vessel occlusion because of an underlying subclavian steal (Fig 2).

SAH may occur in $25 \%-70 \%$ of intracranial giant aneurysms. ${ }^{42}$ The rehemorrhage rate is estimated to be $15 \%$ in the first week, ${ }^{43}$ similar to the reported rate of smaller aneurysms. Prevention of short-term recurrent hemorrhage is the primary treatment goal. Primary coiling (even aimed at partial occlusion) is usually effective to prevent recurrent hemorrhage. In a later stage, after the vasospasm period, a more definitive treatment can be considered. ${ }^{44}$

Deconstructive techniques remain safe and effective, with good clinical and angiographic long-term outcomes. ${ }^{45}$ Nonetheless aneurysms may continue to grow due to hypertrophic vasa vasorum and subadventitial hemorrhages. Surgical trapping with bypass may be the only real curative deconstructive technique because it circumvents these growth mechanisms. ${ }^{46}$ The overall mortality rate has been reported to be $21.1 \%$, and the surgical mortality rate, $8.6 \% .{ }^{47}$ On the other hand, reconstructive techniques such as stent-assisted coiling have shown acceptable complication rates, but $59 \%-87 \%$ recanalization rates. ${ }^{48}$ Still, most of these series refer to patients with unruptured aneurysms, and literature regarding ruptured giant aneurysms is scarce.

In our series, $100 \%(2 / 2)$ of the giant aneurysms had an adverse clinical outcome at discharge. One patient experienced disabling embolic infarcts during the procedure, presumably from mural thrombus dislodging after microcatheter manipulation within the aneurysm sac. However, she had made a good recovery on her last follow-up visit (GOS, 5). The other patient died from a hemorrhagic complication, presumably an aneurysm rerupture, despite the use of coils and a good inflow jet reduction (Fig 3). McAuliffe and Wenderoth ${ }^{8}$ reported their series of 11 recently ruptured aneurysms treated with the PED, with 3 giant aneurysms, 2 of which rebled, resulting in death. The reason for this failure may be that flow-diverting stents do not seem to act as pressure diverters ${ }^{49}$ and the aneurysmal wall still has to endure hemodynamic stresses caused by the cardiac pulse wave. Given these unfavorable outcomes, FDSs should be used with extreme caution in acutely ruptured giant aneurysms or as a second-stage treatment if parent vessel occlusion is not possible.

Despite the improvements in the management of aSAH, vasospasm remains an important cause of morbidity and mortality, with delayed ischemic neurologic deficits (symptomatic vasospasm) in $17 \%-40 \% .{ }^{50}$ In theory, after treatment with the PED, vasospasm may promote thrombosis of the covered smaller branches (ie, perforator arteries) because these remain more sensitive to flow reduction. ${ }^{51,52}$ These stents may also interfere with the endovascular treatment of vasospasm if needed because balloon angioplasty is not possible if a jailed branch is affected, leaving intra-arterial drug injections (ie, nicardipine, milrinone) as the only treatment alternative if medical therapy fails. This remains a theoretic concern because evidence is scarce.
We acknowledge several limitations in our series. This is a retrospective nonrandomized series with a small number of patients, with self-reported complication rates and outcomes. Treatment protocols varied from center to center. Our series also included different aneurysm subtypes and a wide range of severity at clinical presentation. Still, it shows that the FDS may be a feasible treatment strategy in the acute or subacute aSAH setting.

\section{CONCLUSIONS}

The FDS may be a feasible treatment option in the acute or subacute setting of selected ruptured aneurysms, especially blister aneurysms. Ruptured giant aneurysms remain challenging for both surgical and endovascular techniques and, at this stage, FDSs should be used with caution in this aneurysm subtype.

Disclosures: Cian O'Kelly_OTHER: proctor fees, Comments: for Pipeline cases at other institutions. Julian Spears_UNRELATED: Grants/Grants Pending: ev3 research grant for aneurysm database. ${ }^{*}$ Thomas R. Marotta—RELATED: Support for Travel to Meetings for the Study or Other Purposes: proctor for ev3 PED, UNRELATED: Consultancy: Evasc Medical Systems Advisory Board, Comments: no money, Patents (planned, pending, or issued): inventor of eCLIPS endovascular flow-diverter device, Comments: no money. ${ }^{*}$ Money paid to the institution.

\section{REFERENCES}

1. D’Urso PI, Lanzino G, Cloft HJ, et al. Flow diversion for intracranial aneurysms: a review. Stroke 2011;42:2363-68

2. Causin F, Pascarella R, Pavesi G, et al. Acute endovascular treatment. ( $<48$ hours) of uncoilable ruptured aneurysms at non-branching sites using Silk flow-diverting devices. Interv Neuroradiol 2011;17:357-64

3. Martin AR, Cruz JP, Matouk CC, et al. The Pipeline flow-diverting stent for exclusion of ruptured intracranial aneurysms with difficult morphologies. Neurosurgery 2012;70:ons21-ons28

4. Kulcsár Z, Wetzel SG, Augsburger L, et al. Effect of flow diversion treatment on very small ruptured aneurysms. Neurosurgery 2010;67:789-93

5. Rasskazoff S, Silvaggio J, Brouwer PA, et al. Endovascular treatment of a ruptured blood blister-like aneurysm with a flow-diverting stent. Interv Neuroradiol 2010;16:255-58

6. Narata AP, Yilmaz H, Schaller K, et al. Flow-diverting stent for ruptured intracranial dissecting aneurysm of vertebral artery. Neurosurgery 2012;70:982-89, discussion 988-89

7. de Barros Faria M, Castro RN, Lundquist J, et al. The role of the Pipeline embolization device for the treatment of dissecting intracranial aneurysms. AJNR Am J Neuroradiol 2011;32:2192-95

8. McAuliffe W, Wenderoth JD. Immediate and midterm results following treatment of recently ruptured intracranial aneurysms with the Pipeline embolization device. AJNR Am J Neuroradiol 2012;33:487-93

9. Report of World Federation of Neurological Surgeons Committee on a universal subarachnoid hemorrhage grading scale. J Neurosurg 1988;68:985-86

10. Molyneux AJ, Kerr RSC, Birks J, et al. Risk of recurrent subarachnoid haemorrhage, death, or dependence and standardised mortality ratios after clipping or coiling of an intracranial aneurysm in the International Subarachnoid Aneurysm Trial (ISAT): long-term follow-up. Lancet Neurol 2009;8:427-33

11. Fiorella D, Woo HH, Albuquerque FC, et al.. Definitive reconstruction of circumferential, fusiform intracranial aneurysms with the Pipeline embolization device. Neurosurgery 2008;62:1115-20, discussion 1120-21

12. Kallmes DF, Ding YH, Dai D, et al. A new endoluminal, flow-disrupting device for treatment of saccular aneurysms. Stroke 2007;38:2346-52

13. Kallmes DF, Ding YH, Dai D, et al. A second-generation, endolumi- 
nal, flow-disrupting device for treatment of saccular aneurysms. AJNR Am J Neuroradiol 2009;30:1153-58

14. Dai D, Ding YH, Kadirvel R, et al. Patency of branches after coverage with multiple telescoping flow-diverter devices: an in vivo study in rabbits. AJNR Am J Neuroradiol 2012;33:171-74

15. Fiorella D, Hsu D, Woo HH, et al. Very late thrombosis of a Pipeline embolization device construct: case report. Neurosurgery 2010;67(3 suppl operative):onsE313-14, discussion onsE314

16. Klisch J, Turk A, Turner R, et al. Very late thrombosis of flow-diverting constructs after the treatment of large fusiform posterior circulation aneurysms. AJNR Am J Neuroradiol 2011;32:627-32

17. Kulcsár Z, Houdart E, Bonafé A, et al. Intra-aneurysmal thrombosis as a possible cause of delayed aneurysm rupture after flow-diversion treatment. AJNR Am J Neuroradiol 2011;32:20-25

18. Hampton T, Walsh D, Tolias C, et al. Mural destabilization after aneurysm treatment with a flow-diverting device: a report of two cases. J Neurointerv Surg 2011;3:167-71

19. Chow M, McDougall C, O'Kelly C, et al. Delayed spontaneous rupture of a posterior inferior cerebellar artery aneurysm following treatment with flow diversion: a clinicopathologic study. AJNR Am J Neuroradiol 2012;33:E46-51

20. Turowski B, Macht S, Kulcsár Z, et al. Early fatal hemorrhage after endovascular cerebral aneurysm treatment with a flow diverter (SILK-Stent): do we need to rethink our concepts? Neuroradiology 2011;53:37-41

21. Velat GJ, Fargen KM, Lawson MF, et al.. Delayed intraparenchymal hemorrhage following Pipeline embolization device treatment for a giant recanalized ophthalmic aneurysm. J Neurointerv Surg 2012;4:e24

22. Cruz JP, Chow M, O'Kelly CJ, et al. Delayed ipsilateral parenchymal hemorrhage following flow diversion for the treatment of anterior circulation aneurysms. AJNR Am J Neuroradiol 2012;33:603-08

23. Meckel S, Singh TP, Undrén P, et al. Endovascular treatment using predominantly stent-assisted coil embolization and antiplatelet and anticoagulation management of ruptured blood blister-like aneurysms. AJNR Am J Neuroradiol 2011;32:764-71

24. Bodily KD, Cloft HJ, Lanzino G, et al. Stent-assisted coiling in acutely ruptured intracranial aneurysms: a qualitative, systematic review of the literature. AJNR Am J Neuroradiol 2011;32:1232-36

25. Mizutani T, Aruga T, Kirino T, et al. Recurrent subarachnoid hemorrhage from untreated ruptured vertebrobasilar dissecting aneurysms. Neurosurgery 1995;36:905-11, discussion 912-13

26. Rabinov JD, Hellinger FR, Morris PP, et al. Endovascular management of vertebrobasilar dissecting aneurysms. AJNR Am J Neuroradiol 2003;24:1421-28

27. Ramgren B, Cronqvist M, Romner B, et al. Vertebrobasilar dissection with subarachnoid hemorrhage: a retrospective study of 29 patients. Neuroradiology 2005;47:97-104

28. Ogawa A, Suzuki M, Ogasawara K. Aneurysms at nonbranching sites in the supraclinoid portion of the internal carotid artery: internal carotid artery trunk aneurysms. Neurosurgery 2000;47:578-83, discussion $583-86$

29. Ishikawa T, Nakamura N, Houkin K, et al. Pathological consideration of a "blister-like" aneurysm at the superior wall of the internal carotid artery: case report. Neurosurgery 1997;40:403-05, discussion 405-06

30. Shimizu H, Matsumoto $Y$, Tominaga T. Non-saccular aneurysms of the supraclinoid internal carotid artery trunk causing subarachnoid hemorrhage: acute surgical treatments and review of literatures. Neurosurg Rev 2010;33:205-16

31. Gaughen JR, Hasan D, Dumont AS, et al. The efficacy of endovascular stenting in the treatment of supraclinoid internal carotid artery blister aneurysms using a stent-in-stent technique. AJNR Am J Neuroradiol 2010;31:1132-38
32. Lee BH, Kim BM, Park MS, et al. Reconstructive endovascular treatment of ruptured blood blister-like aneurysms of the internal carotid artery. J Neurosurg 2009;110:431-36

33. Saatci I, Cekirge HS, Ozturk MH, et al. Treatment of internal carotid artery aneurysms with a covered stent: experience in 24 patients with mid-term follow-up results. AJNR Am J Neuroradiol 2004;25:1742-49

34. Cantón G, Levy DI, Lasheras JC, et al. Flow changes caused by the sequential placement of stents across the neck of sidewall cerebral aneurysms. J Neurosurg 2005;103:891-902

35. Cantón G, Levy DI, Lasheras JC. Hemodynamic changes due to stent placement in bifurcating intracranial aneurysms. J Neurosurg 2005; 103:146-55

36. Liou TM, Li YC. Effects of stent porosity on hemodynamics in a sidewall aneurysm model. J Biomech 2008;41:1174-83

37. Consoli A, Nappini S, Renieri L, et al. Treatment of two blood blister-like aneurysms with flow diverter stenting. J Neurointerv Surg 2012;4:e4

38. Yamada M, Kitahara T, Kurata A, F et al. Intracranial vertebral artery dissection with subarachnoid hemorrhage: clinical characteristics and outcomes in conservatively treated patients. J Neurosurg 2004;101:25-30

39. Fusco MR, Harrigan MR. Cerebrovascular dissections: a review. Part I, spontaneous dissections. Neurosurgery 2011;68:242-57

40. Andaluz N, Zuccarello M. Blister-like aneurysms of the anterior communicating artery: a retrospective review of diagnosis and treatment in five patients. Neurosurgery 2008;62:807-11, discussion 811

41. Abe M, Tabuchi K, Yokoyama H, et al.. Blood blisterlike aneurysms of the internal carotid artery. J Neurosurg 1998;89:419-24

42. Parkinson RJ, Eddleman CS, Batjer HH, et al. Giant intracranial aneurysms: endovascular challenges. Neurosurgery 2006;59(5 suppl 3):S103-12, discussion S3-13

43. Khurana VG, Piepgras DG, Whisnant JP. Ruptured giant intracranial aneurysms. Part I. A study of rebleeding. J Neurosurg 1998;88:425-29

44. van Rooij WJ, Sluzewski M. Endovascular treatment of large and giant aneurysms. AJNR Am J Neuroradiol 2008;30:12-18

45. Clarençon F, Bonneville F, Boch AL, et al. Parent artery occlusion is not obsolete in giant aneurysms of the ICA: experience with verylong-term follow-up. Neuroradiology 2011;53:973-82

46. Krings T, Mandell DM, Kiehl TR, et al. Intracranial aneurysms: from vessel wall pathology to therapeutic approach. Nat Rev Neurol 2011;7:547-59

47. Piepgras DG, Khurana VG, Whisnant JP. Ruptured giant intracranial aneurysms. Part II. A retrospective analysis of timing and outcome of surgical treatment. J Neurosurg 1998;88:430-35

48. Crobeddu E, Lanzino G, Kallmes DF, et al. Review of 2 decades of aneurysm-recurrence literature. Part 1. Reducing recurrence after endovascular coiling. AJNR Am J Neuroradiol 2013;34:266-70

49. Schneiders JJ, Vanbavel E, Majoie CB, et al. A flow-diverting stent is not a pressure-diverting stent. AJNR Am J Neuroradiol 2013;34:E1-4

50. de Oliveira JG, Beck J, Ulrich C, et al. Comparison between clipping and coiling on the incidence of cerebral vasospasm after aneurysmal subarachnoid hemorrhage: a systematic review and meta-analysis. Neurosurg Rev 2007;30:22-30, discussion 30-31

51. Kulcsár Z, Ernemann U, Wetzel SG, et al. High-profile flow diverter (Silk) implantation in the basilar artery: efficacy in the treatment of aneurysms and the role of the perforators. Stroke 2010;41:1690-96

52. van Rooij WJ, Sluzewski M. Perforator infarction after placement of a Pipeline flow-diverting stent for an unruptured A1 aneurysm. AJNR Am J Neuroradiol 2010;31:E43-44 